\title{
A Cor dos Alimentos
}

\author{
CELESTE DA QUFIJA. M. A. QUEIRÓS e LÍGIA M. RODRIGUES*
}

\section{INTRODUÇÃO}

Os alimentos naturais são de uma forma geral corados sendo, assim, a sua cor parte integrante da nossa cultura e prazer de viver. Já as primeiras civilizaçöes reconheciam que as pessoas também "comem com os ollios" e a adiçäo de corantes naturais ans alimentos é praticada há sćculos. O açafrão e outras especiarias foram usados trequentemente para colorir de amarelo vários alimentos e sabe-se, tamberm, yue a mankeiga começou a ser corada de amarelo no início do século XIV.

lioje em dia lodos us corantes alimentares sāo cutdadosamente regulamentados pelas autoridades compelentes para assegurar que us alimentos que os contêm estão converientemente rotulados e que sào seguros em termos de saúde pública.

Os conantes alimentares podem dividir-se em dois grupos: os sintéticos ique antes de serem usados na alimentação são sujeiros a certificaçầ) cos isolados de fontes naturais. tais como veyetais, minerais mais ou us seus análogos de síntese. Por excmplo, a cor de caramelo é produzida comerciaimente aquecendo açúcar e outros hidratos de carbono sm condiçócs rigorosamente controladas para uso em salsichas, behidas riāo alcoólicas e mollhos, entre outros.

Os corantes sintéticos săo muito usados porque a sua capacidade de colorir á superior à da maior parte dos obtidos de produtos naturajs sendo, assim, adicionados aos alimentos em mujto pequenas quantidades. Para alérm disso, são mais estáveis. produzem cores mais uniformes e misturam-se facilmente uns com os outros para dar uma grande variedade de tonalidades. Normalmente estes corantes nado couferem sabor desagradável ao contrário de alguns naturais como, por exemplo, os derivados da beterraba.

\section{I Porquê o uso de corantes} nos alimentos?

A cor é uma propriedade importante ders alimentes que aunicnta o nosso prazer de comer. A natureza cedo ros ensinou a associar cores ans alimentos, pelo que a sua aceitabilidade está dependente da satisfação desta expectativa.

A variação da cor nos alimentos ao longo das estaçioes c os cefeitos do processamento e da armazenagem requerem muitas ve7es que os industriais adicionem cor aos alimentos para os tornar mais atractivos aos olhos dos consumidores. As principais razōes para a adição de cor aos alimentos incluem:

- Restabelecer a perda de cor devido à exposição à luz, calor, temperaturas elevadas, humidade e condiçoes de armazenagem;

- Corrigir variaçós naturais da cor que muitas vezes são, incorrectaménte, associados à má qualidade. Por exemplo, algumas laranjas são pulverizadas com Citrus Red $n^{12} 2$ (corante nảo permitido na UE) para corrigir a cor natural castanho alaranjado ou manchas verdes da casca;

- Realçar a cor associada a dado alimento quando naturalmente ocorre menos intensa:

- Reproduzir a cor identificaliva de um alimento. Por exemplo, a cor vermelha dá identidade a um gelado de morango:

- Dar aparência colorida à "alimentos engraçados". Por exemplo, a coloração de guloseimas para thes dar un ar festivo.

Nas primeiras décadas deste século havia já cerca de vitenta coran tes sintéticos disponiveis para $1150 \mathrm{em}$ alimentos, nảo existindo qualquer regulamentação sobre a sua pureza e segurança. Entretanto, em vários países loram criadas comissōes para o estudo destes corantes, nomeadamerte da sua toxicidade. No plano internacional é da maior importância - trabalho electuado pela Comissão de Especialisias de Aditivos Alimentares (IECFA), que funciona desde 1956 como organismo consultivo para a FAO, a OMS e o Comité do Codex Alimentarius. A FAO C a OMS publicaram en 1973 e depois em 1979 listas de aditivos resultantes dos trabalhos daquele comité. Estas listas são revistas periodicamente tendo em conta os resulrados de experiências toxilógicas novas.

Na Uniāo Europcia a primeira directiva comunitária que lista os corantes alimentares permitidos e os respectivos critérios de pureza é de 1962 (Documento 362L2645). Fsta directiva foi posteriormente modificada eliminando alguns dos corantes e redefinindo os critérios de pureza. Tanto quanto ć do nosso conhecimento a lista permitida actualmente é a contemplada na Directiva $94 / 36 / \mathrm{CE}$ do Parlamento Furopeu [1].

Como exemplo, refere-se que no Reino Unido em 1957 eram permitidos 32 corantes, em 1973 foram eliminados i 9 e' acrescentados 3 e em 1979 apenas foi atribuído o código E da CEE a 11 destes corantes. Actualmente a lista permilida inclui mais cinco corantes que mà̃o são necossariamente permitidos em todos os paises da UE [2]. Nos Estados Unidos, actualmente, só são permitidos 9 corantes sintéticos alimentares dois dos quais (Citrus Red n" 2 e Orange B) só para aplicaçōes especiais [3].

Os países diferem no que consideram ser seguro e os corantes podem não ter um uso geral. Neste aspecto a Noruega proibiu o uso de corantes sintélicos $\mathrm{im}$ 1976. Em Porugal desconhectmos a existência de lista de corantes permitidos, sendo, reste caso, aplicada a Dircctiva $94 / 36 / \mathrm{CE}$.

1.2 É segura a utilização de corantes sintéticos alimentares?

A questāo da segurança para a saúde pública da utilizaçẫo de corantes alimentares é polénica. No entanto, dos inúneros estudos feitos pode concluir-se que a maior parte pode causar reacçôes alérgicas particularmente em pessoas que demonstram alguma scrsibilidade nomeadamente os asmáticos.

Na tabela 1, onde se apresenta uma listagem de corantes alimentares com os respectivos códigos E. e FDfC ( Federal Food, Drug and Cosmetic Act), incluem-5c os efeitos toxicológicos conhecidos e restriçoes postas por alguns paises. Indica-se. 
Tabcla I - Lista de corantes sintéticos alimentares

\begin{tabular}{|c|c|c|c|c|}
\hline Código & Nome/Cor & Utilizaçíno usual & Comentários & DDA \\
\hline $\begin{array}{l}\text { Elde } \\
\text { FDRC } \\
\text { yellow } n^{3} 5\end{array}$ & $\begin{array}{l}\text { Tatrirazina } \\
\text { Amarel }\end{array}$ & $\begin{array}{l}\text { Pastelaria. confeitaria. } \\
\text { licoses, } \\
\text { sobremesas } \\
\end{array}$ & $\begin{array}{l}\text { Rescçūes alérgicas em algumas } \\
\text { pessoas }\end{array}$ & 0.7 .5 \\
\hline E104 & $\begin{array}{l}\text { Amarelo de } \\
\text { Quinolina }\end{array}$ & $\begin{array}{l}\text { Confeitaria. bebidas, } \\
\text { licores }\end{array}$ & $\begin{array}{l}\text { Năo permitido na Austrälía e EUA } \\
\text { Dermatite de coslacto }\end{array}$ & $0-0.75$ \\
\hline $\begin{array}{l}\text { ETIn } \\
\text { FDEC } \\
\text { yellow } n^{\circ} 6\end{array}$ & $\begin{array}{l}\text { Amarelo-Sol } \\
\text { FCF }\end{array}$ & $\begin{array}{l}\text { Bebiobas. xaropes. } \\
\text { pastelaria. confeitaria }\end{array}$ & $\begin{array}{l}\text { Lrticaria alergias. vómilos, } \\
\text { Broncoconstriçấo (combinado com } \\
\text { Amarante. Ponceau) }\end{array}$ & $0-2.5$ \\
\hline E122 & $\begin{array}{l}\text { Azorubina } \\
\text { Vermelho }\end{array}$ & $\begin{array}{l}\text { Babidas xaropes. } \\
\text { confeitaria }\end{array}$ & $\begin{array}{l}\text { Nẫo permitido nos ELA Nãa } \\
\text { recomendado a pessoas com } \\
\text { sennsibilidade e asmaticas }\end{array}$ & $0-2,0$ \\
\hline $\begin{array}{l}\text { E123 } \\
\text { FDdC } \\
\text { red } \pi^{\circ 2}\end{array}$ & $\begin{array}{l}\text { Amarante } \\
\text { Vermelho }\end{array}$ & $\begin{array}{l}\text { Postelaria e } \\
\text { confeilaria }\end{array}$ & $\begin{array}{l}\text { Năo permilido nos El1A. Ltilizaçăo } \\
\text { restrita em França (só caviar). } \\
\text { Urticaria. Broncoconstriçũa (com } \\
\text { Ponceau 4R c Amarelo Sol) }\end{array}$ & $0-0.5$ \\
\hline E124 & $\begin{array}{l}\text { Vermelho de } \\
\text { Ponceau } 4 R \text {. }\end{array}$ & $\begin{array}{l}\text { Confeitaria. } \\
\text { pastularia. xaropes. } \\
\text { bebidas, charcutaria }\end{array}$ & 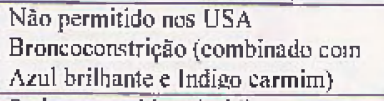 & 0.0 .125 \\
\hline $\begin{array}{l}\text { El27 } \\
\text { FDER } \\
\text { Red n'3 }\end{array}$ & $\begin{array}{l}\text { Eritrosina } \\
\text { Vermaliho }\end{array}$ & $\begin{array}{l}\text { Confeitaria, frulas, } \\
\text { xaropes e } \\
\text { enlatados }\end{array}$ & $\begin{array}{l}\text { Pode eausar hipertiroidsmo e } \\
\text { sersibilidade à Juz }\end{array}$ & $0-2.5$ \\
\hline $\begin{array}{l}\text { E129 } \\
\text { FDdC } \\
\text { Red } \pi^{\circ} 40\end{array}$ & $\begin{array}{l}\text { Alluraked } \\
\text { Vermelho }\end{array}$ & Pastclaria & $\begin{array}{l}\text { Nâo permitido na LE } \\
\text { Tumores/linfomas }\end{array}$ & $0-7$ \\
\hline E131 & $\begin{array}{l}\text { Azul } \\
\text { Patentęado V }\end{array}$ & $\begin{array}{l}\text { Confeitaria. xaropes. } \\
\text { pastelaria, glacés, } \\
\text { licores }\end{array}$ & 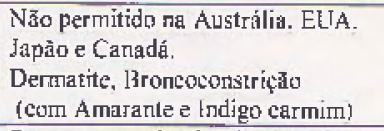 & $0-7,5$ \\
\hline $\begin{array}{l}\text { E132 } \\
\text { FD\&C } \\
\text { Blue } \pi^{\text {d } 2}\end{array}$ & $\begin{array}{l}\text { Indigo } \\
\text { Carmim } \\
\text { Azul }\end{array}$ & $\begin{array}{l}\text { Confeitaria. } \\
\text { pastelaria, glacess c } \\
\text { conteris de frulat }\end{array}$ & $\begin{array}{l}\text { Pessoas com alergias devern evitar, } \\
\text { Pode cansar náuseas. vómitos e } \\
\text { urticatia }\end{array}$ & $0-5,0$ \\
\hline $\begin{array}{l}\text { E133 } \\
\text { (FD\&C Blue } \\
\left.\pi^{2} 1\right)\end{array}$ & $\begin{array}{l}\text { Erioglaucina } \\
\text { Arul } \\
\text { Brilhante } \\
\text { FCF }\end{array}$ & $\begin{array}{l}\text { Rocomendado para } \\
\text { mareaçào de cames na } \\
\text { UE. } \\
\text { Bebidas, gelatinas. } \\
\text { doces e ervilhas } \\
\text { enlatadas }\end{array}$ & $\begin{array}{l}\text { Permilido no RI! } \\
\text { Nao permicido na Austria, Bélgica, } \\
\text { França. Suiça e Suécia. } \\
\text { Erupçóes em algumas pessoas. } \\
\text { tumores de rim en animajs. } \\
\text { Broncoconstriçào (com Eritrosina e } \\
\text { Indigo carniłm) }\end{array}$ & $0-12,5$ \\
\hline $\begin{array}{l}\text { EI } 42 \\
\text { FDdC } \\
\text { Green } n^{2} 3\end{array}$ & $\begin{array}{l}\text { Vurde Acido } \\
\text { Brilhante } \\
\text { FCF }\end{array}$ & $\begin{array}{l}\text { Bebidas. vegetajs } \\
\text { confeitaria, licores, } \\
\text { xaropes. enlatados }\end{array}$ & $\begin{array}{l}\text { Nāo permilido nos EUA. Succia. } \\
\text { Japăo c Canadà. } \\
\text { Pode causar asma s urticárja }\end{array}$ & $0-5,0$ \\
\hline Et51 & $\begin{array}{l}\text { Negro } \\
\text { Brilhante BXy }\end{array}$ & Confeitaria, glacés & $\begin{array}{l}\text { Nầ permitidoi nos EUAA } \\
\text { Pode crusar reacçōes alÉrgicas }\end{array}$ & $0-0.75$ \\
\hline
\end{tabular}

ainda, a Dose Diária Admirida (DDA) definida pelo JECFA e expressa em mg de corante por $\mathrm{kg}$ de peso corporal $[4,5]$. Na figura 1 mostram-se as cstruturas dos corantes constantes da tabela 1 . Tudos estes corantes posstierr grupos polares pelo que apresentan solubilidade en águı.

parece ser consensual que dos corantes permitidos os que apresentam mais problemas săo a tartrazina (El02), o amarelo sol (El l0), a critrosina (E.127) e o amarame (E 123): os três primeiros provocam seguramente reaç̄ones alérgicas e o último admite-se ser cancerígeno tendo sido cntrctanto proibido cm França.
Perante as observaçóes de que há possibilidade de alyurs cfeitos adversos decorrentes da ingestän destes aditivos a questăo da rotulagem pồse com maior acuidade para que us consumidores, eventualmente $\mathrm{d} t$ risco, possam seleccionar com segurança os alimentos.

\section{IDENTIFICACĀO E QUANTIFICAÇĀO DE CORANTES SINTÉTICOS NOS ALIMENTOS}

A quantidade e variedade de guloseimas coloridas ipastilhas elás
Licas, rebuçados, chupa-chupas, elc.) disponiveis no mercado levantam a questāo de saber quais os corantes e cm que quantidade estāo presentes nestes produtos.

Por oulro lado, são as críanças e os jovens os consumidores alvo, especialmente de produlos disponíveis en locais próximos de Escolas. muitas vezes vendidos avulso a como tal sem qualquer menção aos ingredientes. Faz, assim, senuido um trabalho de análise qualitativa e/ou quantitativa de corantes neste tipo de produtos pois dá aos alunos de quimica a oportunidade de. usando produtos seus conhecidos. tomaren consciencia da importância da quinica no controlo de qualidade dos alimentos e nos eventuais perigos para a sua saúde.

Propōe-se un thérodo simples tque usa equipamento polico sofisticado. para que os professores de quimica pussan repetir as experiências não só para ilustrar algumas técnicas. nas lambem para consciencializar os jovens para a química, a alimentação e a saúde. O mútodo descrito há alguns anos por Dixone Renyk [6] procnche os requisitos enunciados, sendo por isso proposto neste trabalho.

\subsection{Descrição das experiências}

Fez-se a análise de uma varicdade de "alimentos" coloridos que inclui pastillas elásticas de urês formas é várias cores, vendidas sem qualquer referência ao conteúdo dos corantes, chupa-chupas, rebuçados, drageias de chocolatu de várias cores, gelatinas (tutli-frutti e amorah, corantes e enfcites para bolos e concentrados de frutus ein pó [7].

O isolamento dos corantes presentes nos materiais estudados $\mathrm{kn-}$ volve três passos: solubilização das aTrostras em ảgua, lixaçāo do corante em lâ e extraccăo do corante com água [6]. O mélodo uxpcrimenta] é descrito em detalhe no Anexo.

Após o isolatrento dos corantes fecz-se a sua identificação por cromatografia em camata fina (CCF) por comparação com corantes padrāo. 

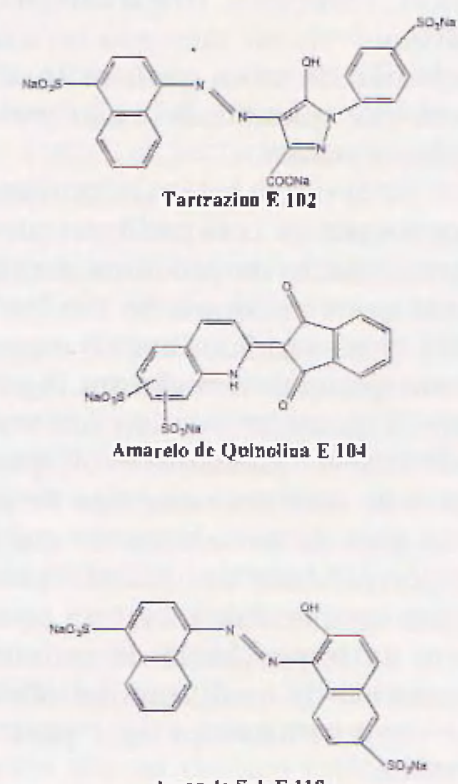

Amarto Sol E 110
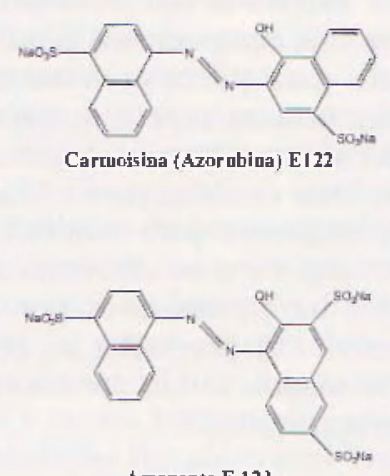

Amarante E 123

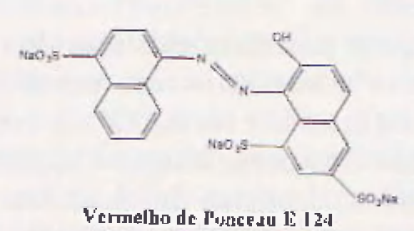

Vermelho de Proncesu E 134

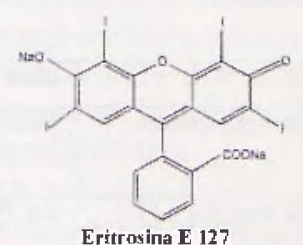

Eritrosina E 127

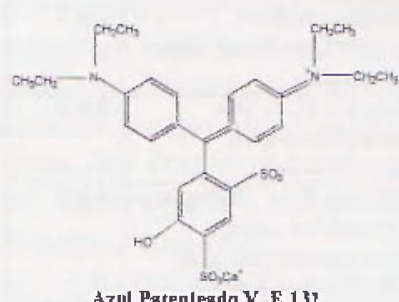

Azul Parenleada V E 1.31
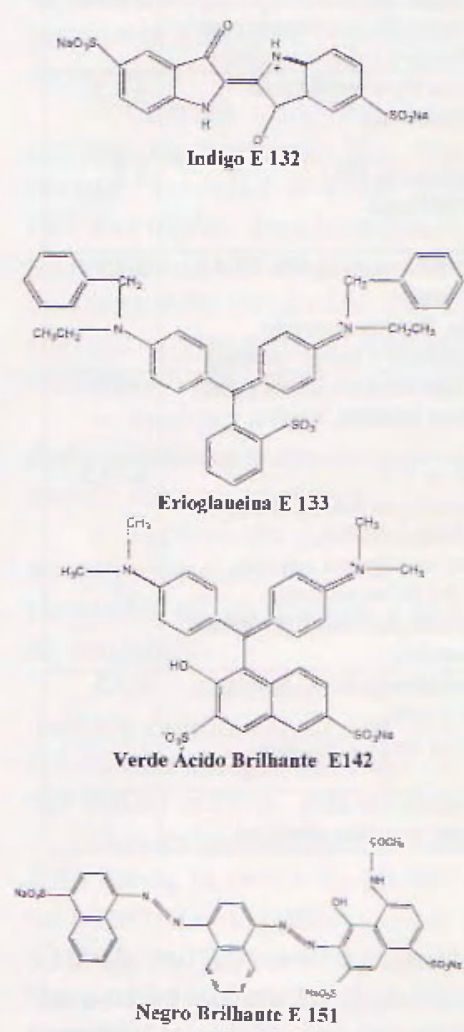

Negro Irrilhante $\mathbf{F} 151$

Flg. T - Estruituras de alguns cor.uiles alimenlares

Usou-se também a espectroscopia de absorção no UV/Vis para confirmar os resultados da cromatografia em camada fina e quando não se dispunha dos corantes padrăo. Nestes casos usaram-se, para comparação. os dados disponiveis na literat ura $|8|$ que se indicam na tabela 3.

No caso da amostra conter um só corante fez-sé a sua quantiticação pelo método da curva padrão ou aplicando a lei de Beer-lambert usando valores tabelados I8/ (AmareIo sol $E_{485 \mathrm{~mm}}=25000 \mathrm{~mol}^{-1} \mathrm{dm}^{3} \mathrm{Clll}^{-2}$; Ponccau $\left.\varepsilon_{505 \mathrm{rm}}=26000 \mathrm{~mol}^{-1} \mathrm{dm}^{3} \mathrm{Clll}^{-1}\right)$. Para amostras com dois corantes usou-se o método das determinaçōes espectrofométricas simultâneas.

\section{RESULTADOS}

Dos vários materiais cstudados apresentam-se os resulados considerados mais representativos em termos do consumo pelos jovens.

Tabela 2 - Vajores de $\mathrm{R}_{\mathrm{f}}$ para os condites paủrăı

\begin{tabular}{|c|c|c|}
\hline Caranle & Cor & $R_{r} \simeq 100$ \\
\hline Indigo Camim & Azul & 55,4 \\
\hline Amarnate & Vermelho Carmin & 45.9 \\
\hline Tarlraxing & Armaralo & 45,9 \\
\hline Erioglaucixa & Arul & 51.4 \\
\hline Fríltosisy & Vernelho Carmin & 72.9 \\
\hline $\begin{array}{l}\text { Yerde Aclido } \\
\text { Brithanle FCF }\end{array}$ & Arullwarde & 421 \\
\hline
\end{tabular}

Na tabela 2 aprescontan-se valores tipicos de $\mathrm{K}_{\text {[ }}$ oblidos para um conjunto de corautes padrāo.

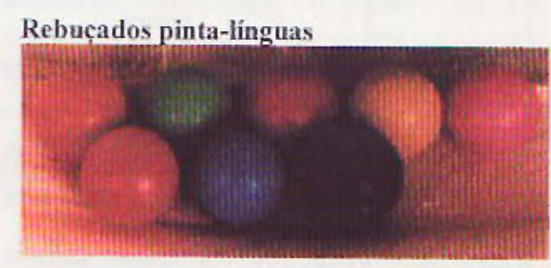

Cromatograma
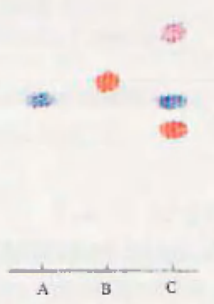

F.spectros de Ultraviolela/visivel

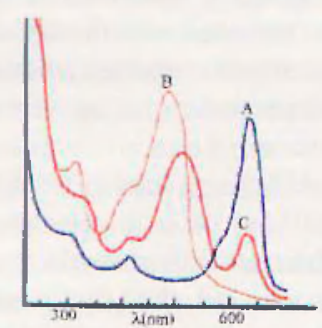

Fig - I- Cromalugramas e espectros do absorcao

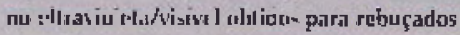
pínla-ffnguas. A - Azul: \$ - Laranja: C - Carmim 


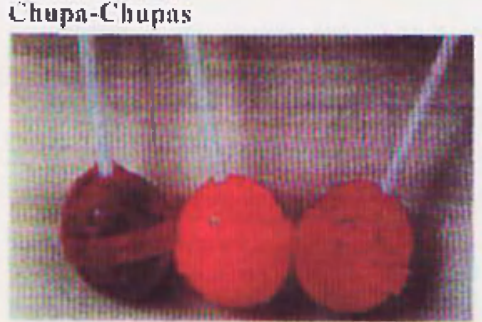

Cromatograma

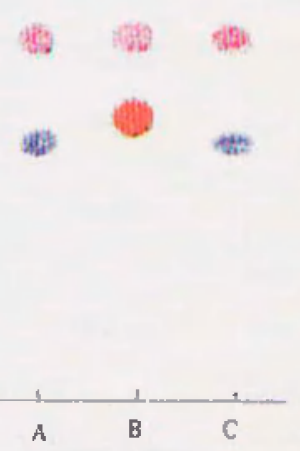

Espectros de ultravioleta/visivel

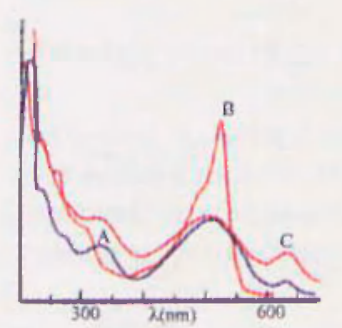

Fìn. 3- Cromaingramas e espectros de absorçāo no ultravioleta/visivel nhlidos para chupa-thupis. A-Rnxu; B - Laranja; C - Vermetho

A análise de rebucados pintalínguas. chupa-chupas e pastilhas elâsticas wvais e drageias de chocolate permitiu, após realizaçāo das experiencias I e 2, obter os cromatogramas e us espectros de absorção no UV/Vis apresentados nas figuras 2,3 , 4 e 5 , respectivamente.

Na tabela 3 resumem-5e os resultados obidos por cromatografia em camada lina e espectroscopia de UV/Visivel para algumas das amostras analisadas.

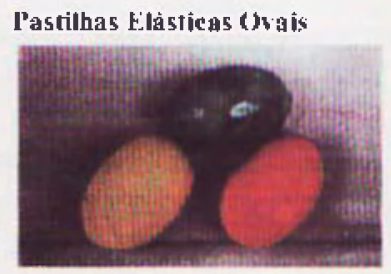

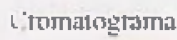

$$
\text { simit }
$$

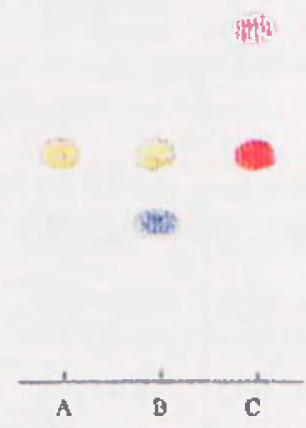

Fspectros de ultravioleta/visivel

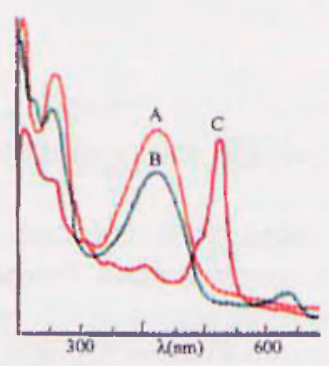

Fig- 4. Cromatugramar e espectros de absorçío nu ularavialeta/visivel ob|idos para pastilhas elísicas ovaiș. A - Amarcla: B - Verut; C - Rom

Na aluela 4 apresentam-se resultados da quantilicaçào dos corantes encontrados em algumas amostras.

\section{CONCLUSŌ̃S}

Os traballoos experimentais apresentados podem ser facilmente realizados num laboratório de quînica minimamente equipado e podem aplicar-se a uma prande variedade de alimentos coloridos.

Dos resultados apresentados pode concluir-se que algumas gulo-

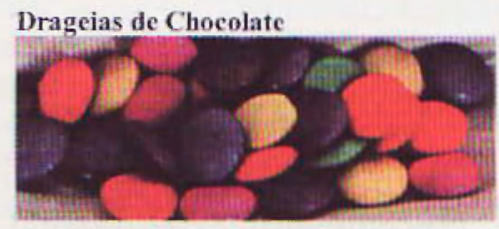

Cromatograma

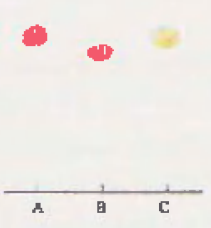

Espectros de uliravioleta/visivet

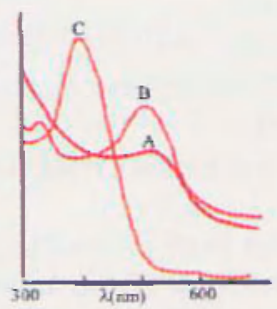

Fig- 5: - Eromalogramas e espectros de absorç̌̀o no ull:raviulela/visivel abtidos pira drageins de chucolale. A - Rosa; B - Carmim; C - Amarela

seimas contem corantes comu a erioglaucina (EI 33 ) que ć probbida em muitos países da Uniāo Europeia e o amarante (E L 23) yuc ć suspetio de ser cancerígeno.

Os resultados obtidos mostram que as quantidades de corantes aticionados em cada unidade sào pequenas. Contudo, sendo as crianças os principais consumidores ce relativamente lácil elas ingerirem quanilidades excessivas dos corantes com valores mais baixos tia dose diária admissivel. Para uma criança te 20 $\mathrm{kg}$ a ingestão de apenas uma pastillia elàstica cilindrica Lasıa para atingir $30 \%$ da dose diária admissivel do corante Ponceau atR 20 rebucados de cereja excedem a dose diaria admissivel de amarante.

Nāo resıam dúvidas que a inclusão deše tupo de alimentos na dieta 


\section{ANEXO}

\section{Procedimento experimental}

\section{Reagentes}

Ácidu acético glacial

$\mathrm{NH}_{4} \mathrm{OH} 0,88 \mathrm{M}$

Isop)ropanol

Tärtrazina, Amarante, Eritrosina (Aldrich)

Indigo Carmin. Erioglaticina. Verde Acido Brilhante FCF (Sigma)

\section{Materiais}

Lã de ovel ha nāo tratada (nāo lavada nem. branqueada)

Amostras a analisar (pastiłlıs elästicas, chupa-cluppas, tebuçados, etc.)

\section{COPOS DE $50 \mathrm{E} 100 \mathrm{ML}$}

Provela de $50 \mathrm{ml}$

Placa de aq̨uecimento

Piacas para cromatografia em camada fina

Tubos capilares

Tina para cromatografia (Pode usar-sr um copo de $400 \mathrm{mi}$ tapado com um vidro de relógio)

Balão de diluição de $25 \mathrm{ml}$

Células de vidoro (Vis) ou quarzzo (UV/Vis)

Fspecirofutómetro de absorção no UV/Vis

\section{Solubilização é extraccão dos corantes:}

Coloca-sc, num copo de $100 \mathrm{ml}$, a "amostra" em água $(30 \mathrm{ml})$ acidificada $\mathrm{com} 3$ gotas de ácido acético glacial para dissolver o corante.

Corta-se a lã de ovelha em tiras de cerca de $20 \mathrm{~cm}$. Estas são fervidas em água $(50 \mathrm{ml}) \mathrm{com} 8$ gotas de hidróxído de amónio $0,88 \mathrm{M}$ e depois lavadas e fervidas de novo em água. Intruduz-se uma tira na sol ução aquosa do corante c leva-se à ebulição até que a sua cor desapareça (cerca de 10 minutos). Relira-se a lã corada, lava-se com água fria e introduz-se num copo de $50 \mathrm{ml}$ contundo água $(20 \mathrm{ml} / \mathrm{com} 3$ gotas de hidroxido de amónio $0.88 \mathrm{M}$. Leva-sc à tbulição para extrair os corantes para a água.

\section{Experiêncía I}

\section{Cromatografia em camada fina}

A soluçäo preparada anteriormente é concentrada por evaporaçāo.

Numa placa de sílica (gel 60 ) traça-se uma linha a lápis a cerca de $1 \mathrm{~cm}$ da extremidade (linlia du partida). A amosita a analisar e as soluçōes dos corantes padrão em $\mathrm{NII}, \mathrm{OH} 0,88 \mathrm{M}$ são aplicadas con un capilar na linha de partida. Introduz-se a placa numa tina de cromatogralia com o eluente (isopropanol e hidróxido de amónio $0.88 \mathrm{M}$ na proporção $4: 1$ ) e deixa-se desenvolver o cromatograma (cerca de 75 minutos). Retira-se a placa. marca-se a frente do solvente. seca-se e contornam-se as manclias observadas.

\section{Experiêncía 2}

Espcctroscopia de absorçāu no UV/Vis

Trausfere-se a solução dos curantes extraídos para um balão de diluição de 25 ml e perfaz-se o volume com água.

Traçam-se os espectros de absorção usando células de quartzo. 
Tabela 3 - Corantes identificados por cromalografia e espectroscopia de LV/Visivel aas ambosiras analisadas

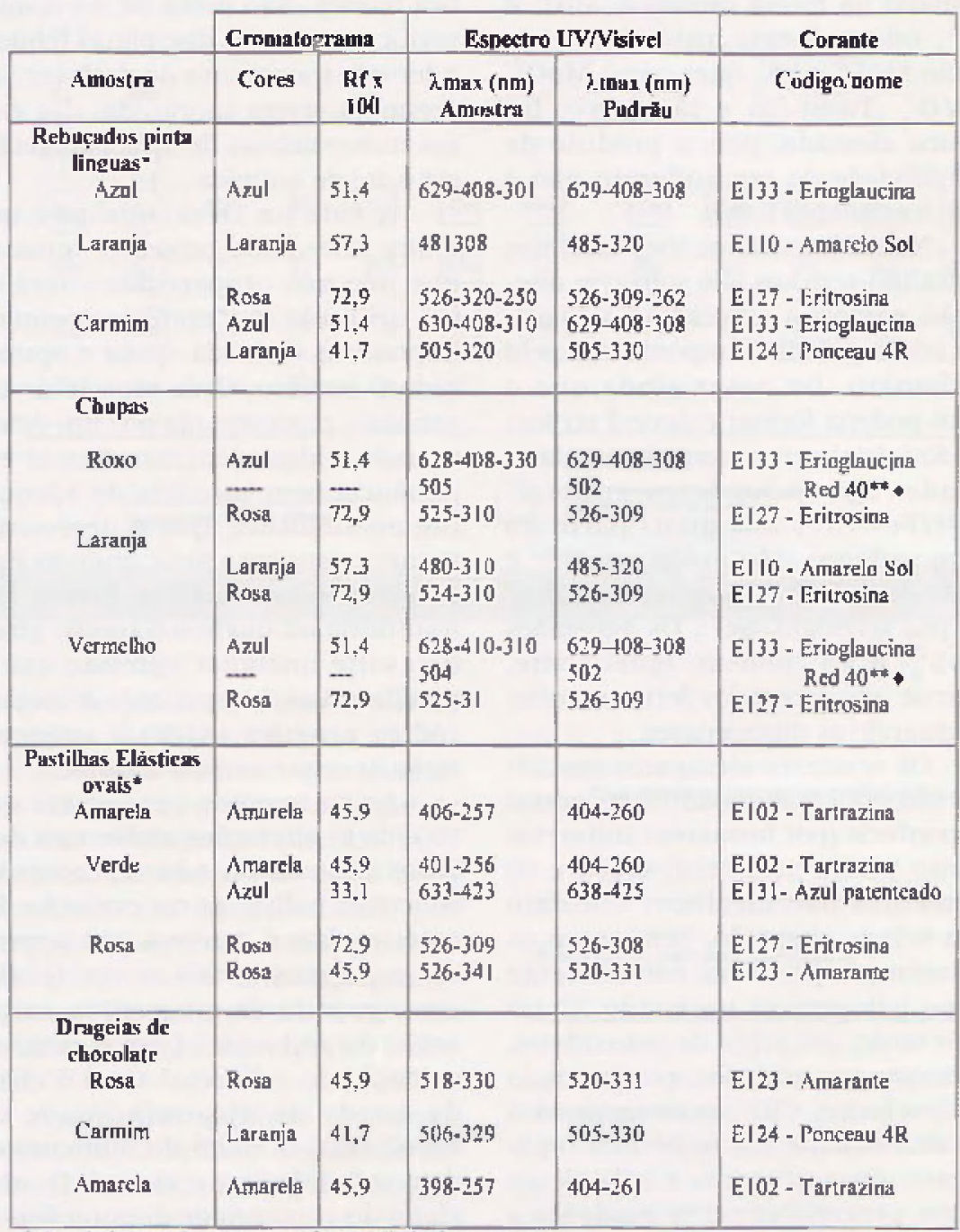

* A embalagen nà cottemi qualquer referénciu āos corantes.

* Referenciado no rósulo

- Năo permitido na UE

Tubcla 4 - Quantidades de corante presentes nas amostras analisadas

\begin{tabular}{|c|c|c|c|c|c|c|}
\hline \multirow[b]{3}{*}{$\begin{array}{l}\text { Corante } \\
\text { Tartrazina } \\
\text { Amarante } \\
\text { Eritrosina } \\
\text { Amarelo Sol } \\
\text { Ponceau 4R } \\
\text { Indiao Carmim }\end{array}$} & \multicolumn{5}{|c|}{$\begin{array}{c}\text { Amostra } \\
\text { Cor / quanlidade ( mofunidade) }\end{array}$} & \multirow[b]{3}{*}{$\begin{array}{l}\text { DDA } \\
7.5 \\
0,75 \\
2,5 \\
5,0 \\
0.125 \\
5.0\end{array}$} \\
\hline & $\begin{array}{l}\text { Pastilltin } \\
\text { eldstics ovul }\end{array}$ & $\begin{array}{l}\text { Drageia de } \\
\text { chocolate }\end{array}$ & $\begin{array}{l}\text { Pastilhs } \\
\text { cilindric }\end{array}$ & istica & $\begin{array}{l}\text { Rebuçada } \\
\text { de cereja }\end{array}$ & \\
\hline & $\begin{array}{ll}\text { Amarela } & 0,96 \\
\text { Rosa } & 0,67 \\
\text { Rosa } & 0.70\end{array}$ & Carmim $\quad 0.28$ & $\begin{array}{l}\text { Leranja } \\
\text { Carmim }\end{array}$ & $\begin{array}{l}0.73 \\
0.75\end{array}$ & 0.193 & \\
\hline
\end{tabular}

diária dos jovens representa um perigo para a sua saúde. É, assim, imporlanue informar e alertar os riscos que os alimemos corados podem apresentar.

A realização de experiências do ripo da apresentada contribui, concerıeza, para chamar a atençào dos consumidores mais jovens para os perigos decortentes da ingesıão abusiva de alimentus corados.

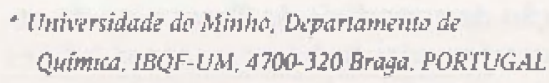

\section{BIBLIOGRAFIA}

I .http $/ /$ mww. ificinfo.heath.org/brochure/ foodcolor.thtml.

2. T.P.Coultate, "Food. The Chemistry of its Components", 2nt Ed. The Royal Sociely of Chemistry. London, 1988, p I53155.

3. hilp:/www.fst.rdg.ac.uk./foodlaw/additive.hinl, "Food Law, Fuod Additives in the European Union".

14. I. L. Multou, "Additifs et Auxilizires de Fabricalion dans les Industries Agroalincentaires, Techniques el Documentation", Lavoisier, Paris, vol. 9, 1984, p 284-285.

5. http//www feingold org/effects.html.

6. E.A. Dixon and G. Renyk, I. Chem. Ed. 59, $\{1-1,(1982), 67-69)$

7. Celeste da Queijar "Separação e identificação de corantes em alimentos". tese de Mestrado, Universidade do Minho. (1994).

8. Dyestuff Commission, "Colours for Foods", VCH. Federal Republic of Germany. 1988. 